\title{
A Proposed Value Engineering System for the Sudanese Construction Industry
}

\author{
Dr. Abdalla M. Awadalla ${ }^{1}$
}

\begin{abstract}
Value Engineering (VE) is defined as a problem solving methodology which is applied in various parts of the world to the construction industry and it proved its effectiveness in optimizing costs and keeping acceptable levels of quality. A young engineer, Lawerence Miles, at the General Electric Company in U.S.A. developed VE methodology in1947. Instead of focusing on the actual part he was assigned to design, he focused attention on the function that it had to perform. VE system can be described as a choice of alternative components. These components when set together form the VE system. Each country chooses the alternative components that suit its economic and environmental conditions. A VE Standard is developed to provide an ideal benchmark of practice in design, construction, operation and maintenance works. Also, the standard is developed to encourage professionals working in the construction field to adopt this technique for improving the value of their projects. The government is expected to adopt this technique and to encourage the engineering departments to organize the application of VE studies on the engineering projects.
\end{abstract}

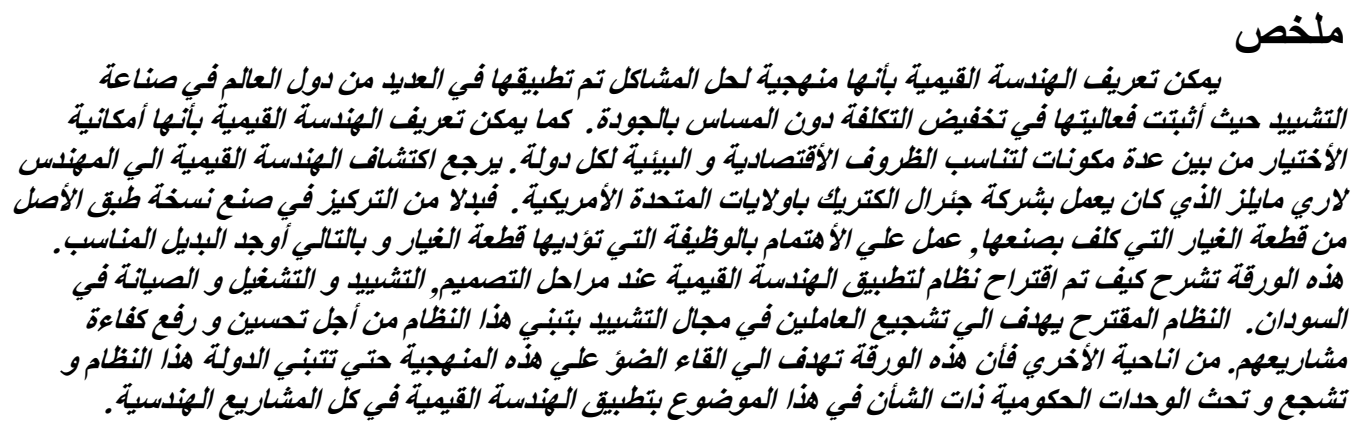

${ }^{1}$ Faculty of Engineering Sciences-Omdurman Islamic University- Fellow (SES) 


\section{Introduction}

Value Engineering (VE) is a systematic application of a recognized approach by a multidisciplined team to identify the functions of a product or a system and to establish a worth for that function. Alternatives are generated through the creative thinking. The needed functions are provided to accomplish purpose of the project, reliability and at the lowest life cycle cost without sacrificing safety, necessary quality and environmental attributes. Most of the countries all over the world have independent systems for practicing VE methodology. The outcome of this practice resulted in a considerable saving in the budget of the construction projects while the quality was improved.

\section{Historical Development of Value Engineering}

Due to the shortage in materials which had happened as a result of the Second World War, a young engineer, Lawerence Miles, at the General Electric Company in U.S.A. developed VE methodology in1947. Instead of focusing on the actual part he was assigned to design, he focused attention on the function that it had to perform. In 1954 this technique was adopted by the American Navy and then it spread among the different departments of the American Army. Millions of dollars were saved due to the application of VE techniques in U.S.A. (Palmer et al.1995). SAVE International (2000) also revealed that the Highway and Transportation departments saved U.S.A. taxpayer one billion dollars in 2000 as a result of implementing VE on highway projects.

Until 1972, the interest of the construction industry firms in this technique was very limited. In the same year, the $12^{\text {th }}$ annual conference of the Society of American Value Engineers (SAVE) encouraged the application of VE in the construction industry (O,Brien 1976). VE techniques spread throughout North America and by the early 1970s; it had been introduced in Japan, Europe and Australia. Today Japan, followed by Germany and the U.S.A. are the biggest users of the system. Other countries that are using this methodology formally include Canada, France, China, Hong Kong, Hungary, Indea, Korea, New Zealand, Saudi Arabia, Taiwan, the United Kingdom and the United Arab Emirates (Grosvenor 1997). Al-Yousifi (2005) stated that the Ministry of Finance in the Kingdom of Saudi Arabia issued a declaration on Ragab 1422 about the application of VE studies on new construction projects. 
Because of the successful VE applications in the Kingdom of Saudi Arabia, it spread to Egypt, Lebanon and Arabian Gulf countries (SAVE International 2000).

Al-Yousifi (2005) reported that there are about 1900 specialists in VE all over the world, $10 \%$ of them are in the Arabian Gulf area conducting 80 to 100 VE studies yearly. The monetary saving of these studies is about five billion SR.

\section{Advantages of the Proposed System}

a) VE is a systematic team effort aimed at improving the value as well as optimizing the life cycle cost. Sudan can achieve a significant success in the field of construction through the application of this methodology. The expected goals to be achieved by the construction industry in Sudan through the application of VE are:

b) Feasible utilization of the national resources.

c) Satisfying the requirements and needs of the body concerned with the project in terms of quality and cost.

d) Achieving good monetary savings in the public construction projects.

e) Construction of the project in one phase using effectively the allocated budget.

f) Use of scientific analysis methods to choose the optimum alternative to carry out the specified project.

g) Design, construction, operation and maintenance stages could be performed with reduced costs.

h) The government should establish a department under the supervision of the Ministry of Finance or any other suitable Ministry to be concerned with this methodology.

A VE Standard is then developed for the following purposes:

a) To provide an ideal benchmark of practice in design, construction, operation and maintenance works.

b) To provide guidelines and common terminology for communication of architects, engineers and other professionals involved in the construction process. 
c) To improve the overall performance of the construction industry in Sudan through the application of VE techniques.

d) To spread the knowledge in this field through conducting seminars and workshops to be attended by internal and external experts of VE.

e) To establish training centers to train architects, engineers, etc. in this methodology.

f) To capture the attention of people, especially the decision makers about VE to convince them to adopt it.

g) To encourage professionals working in the construction field to adopt this technique for improving the value of their projects.

h) To make possible the certification of the different organizations involved in the construction process.

i) The government should issue a circular to all the engineering departments to organize the application of VE studies on the engineering projects. VE studies should be attached as one of the contract documents if the cost of the project is greater than 500 thousand Sudanese pounds.

\section{Development of the Proposed Sudanese Standard of VE}

VE system can be described as a choice of alternative components. These components when set together form the VE system (George, Palmer 1995). Each country chooses the alternative components that suit its economic and environmental conditions. The standard addresses professionals who want to improve value within their organizations and those involved in training and development. The study of different systems adopted in many countries leads to the development of the proposed Sudanese system shown in Table (1): 
مجلة العلوم الهندسيةـ العدد الرابعـ 2009

\begin{tabular}{|c|c|c|}
\hline COMPONENT & ALTERNATIVES & $\begin{array}{l}\text { PROPOSED } \\
\text { ALTERNATIVE } \\
\mathrm{S}\end{array}$ \\
\hline \multirow[t]{3}{*}{ Function definition } & Based on project function & $*$ \\
\hline & Based on space function & \\
\hline & Based on elemental function & \\
\hline Function evaluation & Lowest cost to perform function & $*$ \\
\hline \multirow[t]{2}{*}{ FAST diagram } & Use & $*$ \\
\hline & Do not use & \\
\hline \multirow[t]{2}{*}{ Allocate cost to function } & Yes & $*$ \\
\hline & No & \\
\hline \multirow[t]{2}{*}{ Calculate worth } & Yes & $*$ \\
\hline & No & \\
\hline \multirow[t]{2}{*}{ Generation of alternatives } & Brainstorming & $*$ \\
\hline & Other creative techniques & \\
\hline Organization of study & Job plan & $*$ \\
\hline \multirow[t]{3}{*}{ Group approach } & External team & \\
\hline & Design team & $*$ \\
\hline & Combination & \\
\hline \multirow[t]{2}{*}{ VE facilitator } & Independent & $*$ \\
\hline & In-house & \\
\hline \multirow[t]{3}{*}{ Format of study } & 40 hours workshop & \\
\hline & Two days study & \\
\hline & Other as applicable to the project & $*$ \\
\hline \multirow[t]{2}{*}{ Location } & Outside work environment & \\
\hline & Within work environment & $*$ \\
\hline \multirow[t]{6}{*}{ Timing of study } & Inception & \\
\hline & Brief & \\
\hline & Sketch design & \\
\hline & Construction stage & \\
\hline & Combination of above & \\
\hline & Continuous process & $*$ \\
\hline \multirow[t]{4}{*}{ Evaluation of alternatives } & Weighted matrix e.g. SMART & $*$ \\
\hline & Other mathematical techniques & \\
\hline & Voting & \\
\hline & Subjective evaluation & \\
\hline
\end{tabular}


The choice of the alternative components is as follows:

1. Function definition

Defining the function at the project level will save time and make the VE study more easy, specially in case of large projects. Hence, it is more reliable to select for the proposed system function definition at the project level.

2. Function evaluation:

Lowest cost to perform function is always the best choice for the client.

3. FAST diagram:

The selected alternative is to use function analysis system technique (FAST diagram) to reveal the inter-relationship between the different levels of function definition.

4. Allocate cost to function:

The client is reluctant to know how the estimated cost is shared by the different required functions.

Hence, it is preferable to allocate cost to function.

5. Calculate worth:

Worth is the lowest cost to perform a function. The selected alternative is to calculate worth to obtain the maximum opportunity for improving value.

6. Generation of alternatives:

Brainstorming is the most suitable alternative for the proposed Sudanese system. A great number of ideas are generated and developed deliberately to perform each function at the lowest cost without sacrificing quality.

7. Organization of study:

Job plan is the alternative adopted by most of the countries practicing VE. It is a sequential technique for carrying out a value study. It consists of information, function analysis, implementation and follow-up stages.

8. Group approach:

The alternatives of the group are external team, design team or a combination of both. The main advantage of the external team is that the members of the team are usually highly qualified to study and check the work of the design team. On the other hand, the external team is more expensive and may take more time to understand the project and conduct the study. In addition, the external team will tend to exaggerate on presenting the deficiencies on the design of the 
design team to show their capability. Hence, it seems more logic to choose the design team as a good alternative for the proposed system.

9. VE facilitator:

An independent facilitator should be assigned to guarantee that an external independent body reviews the work of the design team.

10. Format of study:

It is better not to state a definite period for the study since the period depends on the size of the project and other factors.

11. Location:

The selected proposal is within work environment to reduce the expenses of the study.

12. Timing of study:

Continuous process is the most suitable alternative for the economic condition in Sudan.

13. Evaluation of alternatives:

The selected alternative is the weighted matrix-SMART since it gives reliable results compared to other alternatives.

\section{Conclusion}

A VE System was proposed as shown in Table (1) hoping to be developed by researchers and engineers. Great benefits will be gained through the application of VE techniques on the construction projects. Architects and engineers in the public and private sectors should take the first step to adopt this methodology.

\section{References}

1. Al-Yousifi, A. (2005)."Journal interview about VE." J.of Ammar, 90, 26-30.

2. George, D. and Palmer, A. (1995). Construction Management New Direction, Blackwell Sciences.

3. Grosvenor, R. (1997). "Introduction to value management." J.of Value Manager (Hong Kong), 3(4), 11-20.

4. O'Brien, J.J. (1976). Value analysis in design and construction. McGrawHill, New York.

5. SAVE International (2000). Web site: www.value-eng.org. 